\title{
Conditioned taste aversion: modulation by 5-HT receptor activity and corticosterone
}

\author{
Boris Gorzalka*, Laura Hanson, Jennifer Harrington, \\ Sisley Killam, Dan Campbell-Meiklejohn \\ Department of Psychology, University of British Columbia, 2136 West Mall, Vancouver, British Columbia, Canada, V6T 1Z4
}

Received 25 November 2002; received in revised form 31 March 2003; accepted 29 April 2003

\begin{abstract}
Two experiments were designed to elucidate the involvement of the hypothalamic-pituitary-adrenal axis and the 5-hydroxytryptamine (5-HT) system in the acquisition of lithium chloride-conditioned taste aversion. In Experiment 1, rats were administered either vehicle or 50 $\mathrm{mg} / \mathrm{kg}$ nefazodone daily for 4 weeks. Rats were treated with $22 \mathrm{mg} / \mathrm{kg}$ of lithium chloride in order to produce conditioned taste aversion to a sucrose solution. Three days later, nefazodone completely blocked the lithium chloride-conditioned taste aversion. In Experiment 2, the effects of chronic corticosterone administration on lithium chloride-conditioned taste aversion were investigated. Twenty male rats received either corticosterone at a dose of $(50 \mathrm{mg} / \mathrm{kg})$ or vehicle injections over a period of 14 consecutive days. Lithium chloride-conditioned taste aversion was potentiated in rats treated with corticosterone. Additionally, corticosterone-treated animals required more trials to reach extinction. These results suggest the involvement of both the 5-HT system and the hypothalamic-pituitary-adrenal axis in lithium chlorideconditioned taste aversion.
\end{abstract}

(C) 2003 Elsevier Science B.V. All rigths reserved.

\section{Introduction}

Cognitive biases have been implicated in the development and maintenance of major depressive disorder. Depressed patients tend to recall more negative and stressful events (Clark and Teasdale, 1982) and to rate these events as more salient and unpleasant (Schless et al., 1974). It has been suggested that physiological changes, such as high cortisol levels and increased 5-HT receptor density, observed in many patients with depression might be linked to these negative cognitive biases (Lopez et al., 1997; Barden et al., 1995).

A putative model for studying acquisition of negative or stressful events is conditioned taste aversion (Peeters and Broekkamp, 1994). Conditioned taste aversion is a form of associative learning in which animals learn to avoid flavors of substances where ingestion was followed by illness. In conditioned taste aversion, animals learn to

\footnotetext{
* Corresponding author. Tel.: +1-604-822-3095; fax: +1-604-8226923.

E-mail address: bgorzalka@psych.ubc.ca (B. Gorzalka).
}

associate flavors, or conditioned stimuli, with the aversive or toxic effects of administered agents, or unconditioned stimuli. Following conditioned stimuli-unconditioned stimuli pairings, animals reduce their consumption of the conditioned flavor (conditioned stimuli), and/or show a preference for other tastes. Unlike other forms of associative learning, conditioned taste aversion develops rapidly, often following a single conditioning trial (Berendsen and Broekkamp, 1999; Smotherman, 1985). Lithium chloride has been shown to be a powerful unconditioned stimulus leading to the development of conditioned taste aversion in laboratory animals. Animals which are exposed to a novel flavor and subsequently injected with lithium chloride quickly develop a conditioned taste aversion to the novel flavor (Riley and Baril, 1976; Olivier et al., 1999).

Acute injection of lithium chloride increases activity of the hypothalamic-pituitary-adrenal axis resulting in significantly elevated plasma glucocorticoid levels. This increase occurs within an hour of injection and lasts between 2 and $4 \mathrm{~h}$ (Hennessy et al., 1976; Smotherman, 1985). Additionally, mice injected with lithium chloride 
after their first exposure to a sucrose solution failed to develop conditioned taste aversion if they were previously adrenalectomized. This effect was attenuated by a single glucocorticoid injection (either corticosterone or dexamethasone) administered 5 min after the injection of lithium chloride (Peeters and Broekkamp, 1994). These studies suggest that the development of lithium chloride-conditioned taste aversion is dependent upon elevations in plasma glucocorticoids.

Acute administration of lithium chloride also exerts effects upon the 5-HT system. A single injection of lithium chloride enhances the effects of the $5-\mathrm{HT}_{2 \mathrm{~A}}$ receptor agonist 1-2,5-dimethoxy-4-iodophenyl)-2-aminopropane (DOI) (Moorman and Leslie, 1998), and induces 5-HT $\mathrm{HA}_{2 \mathrm{~A}}$-mediated behavioural responses which can be blocked by the administration of the 5- $\mathrm{HT}_{2 \mathrm{~A}}$ receptor antagonist ketanserin (Hotta et al., 1986). Furthermore, administration of the $5-\mathrm{HT}_{1 \mathrm{~A}}$ receptor agonist 8-hydroxy-2-(di- $n$-propylamino)tetralin (8OH-DPAT) attenuates lithium chloride-induced conditioned taste aversion, while 5- $\mathrm{HT}_{1 \mathrm{~A}}$ receptor antagonists, such as pindolol, can actually produce conditioned taste aversion on their own (Wegener et al., 1997). Taken together, these findings suggest that 5- $\mathrm{HT}_{1 \mathrm{~A}}$ receptor antagonism and 5$\mathrm{HT}_{2 \mathrm{~A}}$ receptor agonism play a role in lithium chloride's physiological effects and may therefore be significant in the development of lithium chloride-conditioned taste aversion. However, inhibition of 5-HT synthesis fails to prevent the development of lithium chloride-conditioned taste aversion (Wegener et al., 1997), thus it is reasonable to assume that alternative brain mechanisms are involved.

A considerable amount of research has demonstrated that the hypothalamic-pituitary-adrenal axis and 5-HT system are functionally linked-alterations in glucocorticoid levels result in changes in 5-HT receptor levels and the administration of selective 5-HT agents alters the activity of the hypothalamic-pituitary-adrenal axis (for review, see Chaouloff, 1995). Administration of ketanserin, a 5- $\mathrm{HT}_{2 \mathrm{~A}}$ receptor antagonist (Brogden and Sorkin, 1990), has been shown to attenuate the development of corticosterone-influenced behaviours (Gorzalka et al., 2001).

The following experiments investigate the role of 5-HT receptor activity and glucocorticoids in the development of lithium chloride-conditioned taste aversion. In order to further elucidate the role of the $5-\mathrm{HT}_{1 \mathrm{~A}}$ and $5-\mathrm{HT}_{2 \mathrm{~A}}$ receptors in the development of lithium chloride-conditioned taste aversion, nefazodone, an antidepressant with $5-\mathrm{HT}_{1 \mathrm{~A}}$ receptor agonistic, $5-\mathrm{HT}_{2 \mathrm{~A}}$ receptor antagonistic and 5-HT reuptake inhibition properties (Taylor et al., 1995) was administered. Because the mechanism underlying lithium chloride-conditioned taste aversion is hypothesized to involve $5-\mathrm{HT}_{1 \mathrm{~A}}$ receptor antagonism and $5-\mathrm{HT}_{2 \mathrm{~A}}$ receptor agonism, it was hypothesized that nefazodone administration would attenuate the development of lithium chloride-conditioned taste aversion. In Experiment 2 , animals were chronically treated with corticosterone at a dose known to increase central $5-\mathrm{HT}_{2 \mathrm{~A}}$ receptor density
(Kuroda et al., 1992). Previous studies have suggested the involvement of elevated adrenal glucocorticoids in lithium chloride-conditioned taste aversion. It was expected that animals chronically treated with corticosterone would display potentiated lithium chloride-conditioned taste aversion.

\section{Materials and methods}

\subsection{Experiment 1}

Experiment 1 investigated the effects of the antidepressant nefazodone on the lithium chloride-conditioned taste aversion paradigm in rats. Nefazodone's effect on the 5$\mathrm{HT}_{2 \mathrm{~A}}$ and $5-\mathrm{HT}_{1 \mathrm{~A}}$ receptors is opposite to the effects of acute lithium chloride administration. Specifically, nefazodone has $5-\mathrm{HT}_{2 \mathrm{~A}}$ receptor antagonistic properties and mild $5-\mathrm{HT}_{1 \mathrm{~A}}$ receptor agonistic properties (Taylor et al., 1995). Nefazodone has also been shown to reverse the effects of chronically administered corticosterone. Corticosterone administration increases the occurrence of sexual behaviour and wet dog shakes in the female rat; however, treatment with nefazodone counters this effect (Hanson et al., 1998). Additionally, chronic administration of lithium chloride has been shown to increase adrenal weights and serum corticosterone levels (Ghosh et al., 1990). If the development of conditioned taste aversion is dependent on lithium chloride's effects on 5-HT receptor activity and elevated glucocorticoid levels, then administration of nefazodone should attenuate lithium chloride-conditioned taste aversion.

\subsubsection{Subjects}

Forty male Long Evans rats (Charles River Canada, Montreal) were the subjects of the present experiment. Animals were maintained under a fixed 12-h light/dark cycle (lights on at $0900 \mathrm{~h}$ ) in a temperature-controlled room $\left(21 \pm 1{ }^{\circ} \mathrm{C}\right)$. Prior to the experiment, animals were group housed in hanging triple wire mesh cages (three rats per cage-dimensions D/W/H $=25: 66: 18 \mathrm{~cm}$ ). Food (Purina Rat Chow) and water were available ad libitum. At the time of the experiment, rats were about 9 months old and weighed between 500 and $600 \mathrm{~g}$.

\subsubsection{Procedure}

Rats were randomly divided into four groups: lithium chloride and nefazodone $(n=10)$, lithium chloride and no nefazodone $(n=10)$, no lithium chloride and nefazodone $(n=10)$, no lithium chloride and no nefazodone $(n=10)$. Rats assigned to nefazodone treatment conditions were injected with $50 \mathrm{mg} / \mathrm{kg}$ of nefazodone (Pfizer, USA) dissolved in saline solution; rats assigned to the no nefazodone conditions received saline injections $(1 \mathrm{ml} / \mathrm{kg})$. Injections were administered daily for 4 weeks during the middle third of the dark cycle. Rats remained group housed throughout 
the 4-week injection procedure with free access to food and water.

At the commencement of the present experiment, animals were individually housed in single wire mesh cages (dimensions $\mathrm{D} / \mathrm{W} / \mathrm{H}=25: 21: 18 \mathrm{~cm}$ ). Food was available ad libitum; however, drinking solution access was limited to two daily sessions of 30-min duration (occurring at 0900 and $1600 \mathrm{~h}$ ). Due to restricted access to drinking solutions, all subjects were individually trained to drink when water bottles were made available. Eight 30-min training sessions took place over 4 consecutive days (Days 1-4, two training sessions per day). Training took place in home cages equipped with drinking bottles filled with tap water.

During the morning session of Day $5(0900 \mathrm{~h})$, the water bottles were filled with $100 \mathrm{ml}$ of $5 \%$ sucrose solution. Rats were given a 20 -min drinking session. Immediately following the drinking session, animals assigned to lithium chloride treatment conditions were subcutaneously injected with lithium chloride (22 mg/kg) (Sigma, St. Louis, MO), dissolved in saline solution. Control animals were injected with saline solution $(1 \mathrm{ml} / \mathrm{kg})$.

Following injection, rats remained in their home cages for 2 days (Days 5 and 6) with tap water and food available ad libitum. On Day $7(1630 \mathrm{~h})$, the water bottles were removed. During the morning session of Day 8 , the rats were offered a choice between $100 \mathrm{ml}$ of tap water or $5 \%$ sucrose solution and permitted a 20-min drinking session. To facilitate access to both drinking bottles, food pellets were removed from cages and a second drinking bottle (water or sucrose) was inserted. Drinking bottles were placed in a random order. Sucrose solution intakes (in $\mathrm{ml}$ ) were recorded. Following completion of the experiment, animals were returned to triple wire mesh cages (three rats per cage).

All procedures employed in these experiments were approved by the University of British Columbia Animal Care Committee and the Canadian Council on Animal Care.

\subsection{Experiment 2}

Lithium administration produces a rise in adrenal corticosteroid levels (Smotherman, 1985; Hennessy et al., 1976). Adrenalectomized animals fail to develop lithium chloride-conditioned taste aversion; however, administration of glucocorticoids reverses this effect (Peeters and Broekkamp, 1994). The present experiment examined the effects of chronically elevated corticosterone levels on lithium chloride-conditioned taste aversion. It has been hypothesized that elevated glucocorticoids may enhance the associative learning of aversive events. If elevated corticosteroid levels augment this form of associative learning, it would be expected that experimental animals that had been chronically exposed to corticosterone would show weakened conditioned taste aversions.

\subsubsection{Subjects}

Twenty male Long Evans rats (Charles River Canada) were the subjects of the present experiment. All animals were naïve to the current paradigm. Animals were maintained under a fixed 12-h light/dark cycle (lights on $0900 \mathrm{~h}$ ) in a temperature-controlled room $\left(21 \pm 1{ }^{\circ} \mathrm{C}\right)$. Prior to the experiment, animals were group housed in triple wire mesh cages (three rats per cage). Food (Purina Rat Chow) and water were available ad libitum. At the time of the experiment animals, were 9 months old and weighed between 500 and $600 \mathrm{~g}$.

\subsubsection{Procedure}

Animals remained group housed (three rats per cage) for Days 1-6 of the experiment. On Day 7, animals were transferred into double wire mesh cages (one rat per cage - dimensions $\mathrm{D} / \mathrm{W} / \mathrm{H}=25: 44: 18 \mathrm{~cm}$ ), and drink training began. Double wire mesh cages were equipped with two areas for water bottles and a single area for food.

Animals were randomly divided into two groups $(n=10)$. The experimental group was injected with $50 \mathrm{mg} / \mathrm{kg}$ of corticosterone (Sigma) dissolved in propylene glycol. In addition to increasing $5-\mathrm{HT}_{2 \mathrm{~A}}$ receptor density (Kuroda et al., 1992), this dose elevates plasma corticosterone levels to those seen in animals subjected to acute immobilization stress (Hodges and Jones, 1963), and has been shown to have behavioural effects (Gorzalka and Hanson, 1998; Berendsen et al., 1996). Control animals were injected with $1 \mathrm{ml} / \mathrm{kg}$ of propylene glycol. All injections occurred over a period of 14 consecutive days during the second third of the dark period.

Drink training occurred during Days 7-14. During training, animals were water deprived except for two 30-min daily training sessions (at 0900 and 1600 h). On Day 14 $(0930 \mathrm{~h})$, animals were permitted to drink a 5\% sucrose solution for a period of $20 \mathrm{~min}$. Sucrose solution intakes were calculated for individual rats, and constituted the preconditioning measure.

Immediately following this initial exposure to sucrose solution, all animals were injected with a $22 \mathrm{mg} / \mathrm{kg}$ of lithium chloride and water bottles were removed. At 1600 $\mathrm{h}$, water bottles were returned and rats were left undisturbed in their home cages for a period of 2 days with tap water readily available. On Day 16 at $1630 \mathrm{~h}$ (end time for the second drinking session), water bottles were removed. During the morning session of Day 17, animals were offered a choice between $100 \mathrm{ml}$ of tap water and 100 $\mathrm{ml}$ of 5\% sucrose solution, and permitted a 20-min drinking session. The second drinking bottle was randomly placed in the alternate slot. Rats had free access to food pellets throughout the experiment. Individual sucrose solution intakes (in $\mathrm{ml}$ ) were calculated and constituted the postconditioning measure.

An extinction period was introduced by continuing drinking sessions $(0900$ and $1600 \mathrm{~h})$ for a period of 7 days following the testing session (15 exposures total). For the 
first 2 days of the extinction procedure, animals were offered a drink bottle containing $100 \mathrm{ml}$ of $5 \%$ sucrose solution for a duration of $20 \mathrm{~min}$ at each session. In order to prevent dehydration, animals were permitted to drink tap water for a period of $10 \mathrm{~min}$ following each 20 -min drinking session. Individual sucrose solution intakes were calculated following each drinking session. Following completion of the experiment, animals were returned to triple wire mesh cages (three rats per cage).

\section{Results}

\subsection{Experiment 1}

The conditioned taste aversion was apparent in animals receiving lithium chloride but no nefazodone, $F(1,36)=$ 4.67, $P<0.04$ (Fig. 1). Administration of nefazodone significantly increased sucrose solution intakes in rats treated with lithium chloride, $F(1,36)=39.39, P<0.0005$ (Fig. 1). However, nefazodone treatment in the absence of lithium chloride had no effect on sucrose solution consumption.

Nefazodone treatment blocked the development of conditioned taste aversion in rats treated with lithium chloride. Consequently, the present experiment provides indirect support for the involvement of 5- $\mathrm{HT}_{1 \mathrm{~A}}$ and $5-\mathrm{HT}_{2 \mathrm{~A}}$ receptor activity in lithium chloride-conditioned taste aversion. More specifically, the results support the hypothesis that both 5$\mathrm{HT}_{1 \mathrm{~A}}$ receptor antagonism and $5-\mathrm{HT}_{2 \mathrm{~A}}$ receptor agonism may contribute to the development of conditioned taste aversion in lithium chloride-treated animals.

\subsection{Experiment 2}

As shown in Fig. 2, chronic exposure to corticosterone enhanced the conditioned taste aversion induced by lithium

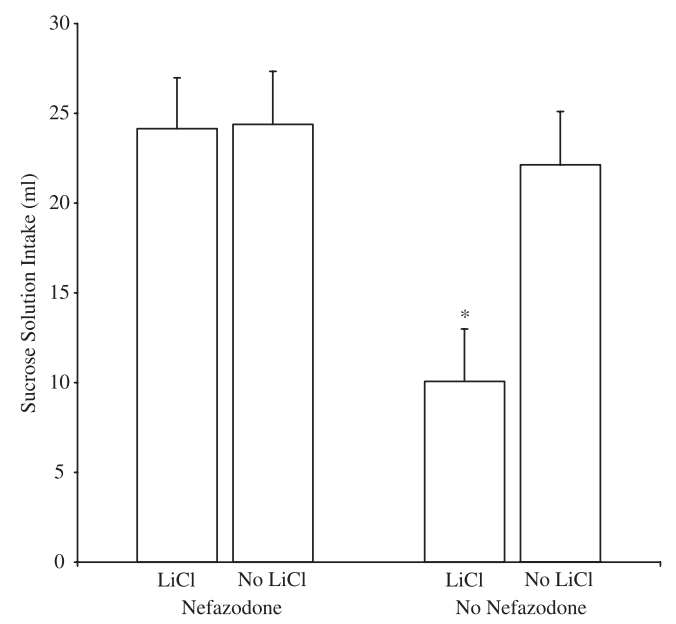

Fig. 1. Effects of nefazodone administration $(50 \mathrm{mg} / \mathrm{kg})$ on lithium chloride-conditioned taste aversion in rats ( $n=10$ per group) as indicated by sucrose solution intakes (mean \pm S.E.M.). ${ }^{*} P<0.0005=$ significantly different from $\mathrm{LiCl}$ and nefazodone, analysis of variance.

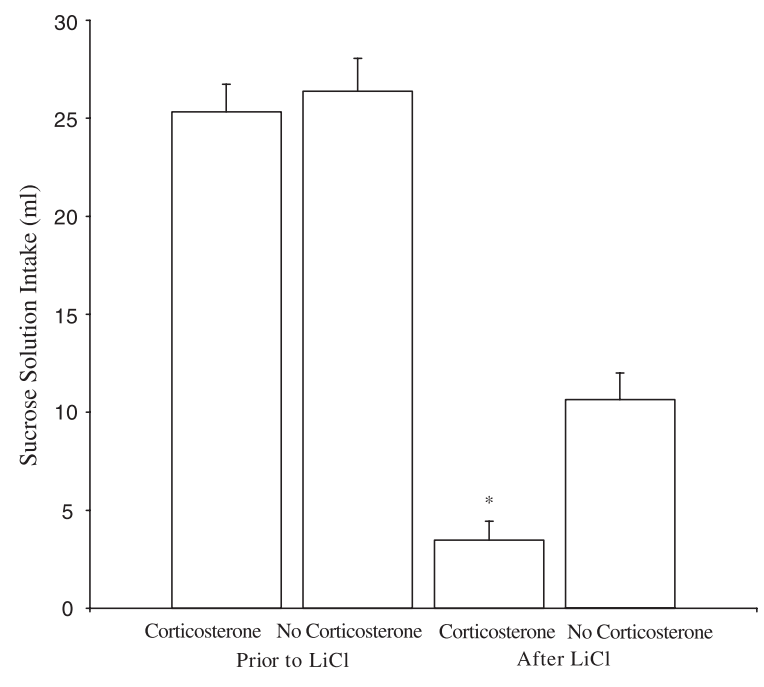

Fig. 2. Effects of corticosterone administration $(50 \mathrm{mg} / \mathrm{kg})$ on lithium chloride-conditioned taste aversion in rats ( $n=10$ per group) as indicated by sucrose solution intakes (mean \pm S.E.M.) prior to and immediately following conditioning. ${ }^{*} P<0.02=$ significantly different from no corticosterone after $\mathrm{LiCl}, t$-test.

chloride injection. A $t$-test for equality of means performed on the differences between pre-conditioning and post-conditioning sucrose intakes of the control and corticosterone groups showed that chronic corticosterone treatment significantly increased the aversive reaction to sucrose in rats injected with lithium chloride, $t(17)=2.56, P<0.02$. That is, rats chronically treated with corticosterone displayed greater conditioned taste aversions. A second $t$-test for equality of means was performed on the number of extinction exposures it took for rats to return to pre-conditioning sucrose consumption levels. Rats treated with corticosterone took significantly more exposures to extinguish the conditioned taste aversion, $t(17)=5.619, P<0.001$. An average of $10.2 \pm 1.6$ exposures was required to extinguish conditioned taste aversions in rats treated with corticosterone compared to $1.5 \pm 1.3$ exposures in rats not treated with corticosterone.

The results of the present experiment indicate that rats chronically treated with corticosterone are predisposed towards associative learning of aversive events.

\section{Discussion}

The results of the present experiments suggest that both the 5-HT system and the hypothalamic-pituitary-adrenal axis mediate conditioned taste aversion. In Experiment 1, administration of nefazodone prevented the development of lithium chloride-conditioned taste aversion. Additionally, corticosterone-treated animals required more trials to extinguish lithium chloride-conditioned taste aversion. Hotta et al. (1986) hypothesized that lithium chloride activates 5$\mathrm{HT}_{2 \mathrm{~A}}$ receptors after observing that acute administration of high doses of lithium chloride-induced wet dog shakes and 
pretreatment with ketanserin, a 5- $\mathrm{HT}_{2 \mathrm{~A}}$ receptor antagonist, blocked the effect. It has been shown that increases in wet dog shakes are correlated with increases in $5-\mathrm{HT}_{2 \mathrm{~A}}$ receptor activity and that chronic administration of corticosterone increases wet dog shakes by increasing $5-\mathrm{HT}_{2 \mathrm{~A}}$ receptor density (Kuroda et al., 1992). Other evidence indicates that the increase in frequency of wet dog shakes is blocked by treatment with either nefazodone (Hanson et al., 1998) or ketanserin (Gorzalka et al., 2001). This evidence, combined with the results of Experiment 1, suggests that increased 5$\mathrm{HT}_{2 \mathrm{~A}}$ receptor activity is an aversive consequence of acute lithium administration which contributes to conditioned taste aversion. Nefazodone's effect on $5-\mathrm{HT}_{1 \mathrm{~A}}$ receptors are only apparent at higher doses; when chronically administered at doses of $100 \mathrm{mg} / \mathrm{kg}$ but not at $30 \mathrm{mg} / \mathrm{kg}$, nefazodone potentiates $5-\mathrm{HT}_{1 \mathrm{~A}}$ receptor agonist-induced forepaw treading (Eison et al., 1990). Since the development of conditioned taste aversion is significantly influenced by $5-\mathrm{HT}_{1 \mathrm{~A}}$ receptor activity (Wegener et al., 1997), we cannot rule out the possibility that $5-\mathrm{HT}_{1 \mathrm{~A}}$ receptor activation contributed to the present results given the 50 $\mathrm{mg} / \mathrm{kg}$ dose of nefazodone used in this study.

In addition to its effects on 5-HT receptors, nefazodone has also been reported to have 5-HT and norepinephrine reuptake inhibiting properties (Taylor et al., 1995). It is doubtful that either of these effects accounts for the present findings. Nefazodone has no effect on norepinephrine reuptake when given chronically at doses in the range used in the present study (Eison et al., 1990). Selective 5-HT reuptake inhibiting antidepressants have been associated with an induction of conditioned taste aversion that is not accounted for by alterations in 5-HT receptor activity (Berendsen and Broekkamp, 1999). Given that nefazodone attenuated a conditioned taste aversion in the present study, it is unlikely that 5-HT reuptake inhibition was responsible for this effect.

The results of Experiment 2 indicate that corticosterone enhanced the magnitude of lithium chloride-conditioned taste aversion, as indicated by reduced sucrose intake, and caused the aversion to persist longer, as indicated by dramatically more trials to extinction. Corticosterone has been shown to increase $5-\mathrm{HT}_{2 \mathrm{~A}}$ receptor activity and decrease $5-\mathrm{HT}_{1 \mathrm{~A}}$ receptor activity. Chronic corticosterone treatment, at levels which mimic conditions of extreme stress, result in an increase in $5-\mathrm{HT}_{2 \mathrm{~A}}$ receptor density (Kuroda et al., 1992; McKittrick et al., 1995) and an increase in $5-\mathrm{HT}_{2 \mathrm{~A}}$ receptor-mediated behaviour (Gorzalka et al., 2001; Kuroda et al., 1992; Hanson et al., 1998; Gorzalka and Hanson, 1998; Berendsen et al., 1996; McKittrick et al., 1995). 5- $\mathrm{HT}_{2 \mathrm{~A}}$ receptor antagonists reverse the behavioural effects of chronic corticosterone (e.g., Gorzalka et al., 2001; Hanson et al., 1998). It seems plausible that the enhancement of conditioned taste aversion by corticosterone is mediated by increased activity at $5-\mathrm{HT}_{2 \mathrm{~A}}$ receptors and/or decreased activity at $5-\mathrm{HT}_{1 \mathrm{~A}}$ receptors.
5-HT and hypothalamic-pituitary-adrenal axis activity and their relationship to learning and memory have clinical relevance for the treatment and prevention of a subgroup of depressive illnesses. Many studies have investigated the physiological mechanisms thought to underlie anxious and depressive cognitive styles, and have implicated the $5-\mathrm{HT}_{1 \mathrm{~A}}$ and $5-\mathrm{HT}_{2 \mathrm{~A}}$ receptors, as well as dysregulation of the hypothalamic-pituitary-adrenal axis. $5-\mathrm{HT}_{1 \mathrm{~A}}$ receptor involvement has been suggested in the etiology of anxious and depressive disorders, and increased $5-\mathrm{HT}_{2 \mathrm{~A}}$ binding sites have been found in the brains of patients with depression and suicide victims (Lopez et al., 1997). Abnormalities in $5-\mathrm{HT}_{1 \mathrm{~A}}$ receptor-mediated responses in depressed patients have also been shown to be a secondary effect of hypersecretion of cortisol (Lesch et al., 1990).

Research has indicated that both elevated glucocorticoids and malfunctioning of the 5-HT system are evident in depressive and suicidal people (Lopez et al., 1997; Checkly, 1992). Perhaps, the degree to which the individual experienced a physiological excess of cortisol, either as a result of exogenous stress or as a result of endogenous disturbance in their hypothalamic-pituitary-adrenal axis, would effect the degree to which they experienced and remembered negative events. This could influence the severity and pervasiveness of their illness.

\section{References}

Barden, N., Reul, J.M., Holsboer, F., 1995. Do antidepressants stabilize mood through actions on the hypothalamic-pituitary-adrenocortical system? Trends Neurosci. 18, 6-10.

Berendsen, H., Broekkamp, C.L., 1999. Antagonism of the 5-HT $\mathrm{HA}_{1 \mathrm{~A}}$ receptor stimulus in a conditioned taste aversion procedure. Eur. Neuropsychopharmacol. 9, 345-349.

Berendsen, H., Kester, R., Peeters, B.W., Broekkamp, C.L., 1996. Modulation of 5-HT receptor subtype-mediated behaviors by corticosterone. Eur. J. Pharmacol. 308, 103-111.

Brogden, R., Sorkin, E., 1990. Ketanserin. A review of its pharmacodynamic properties, and therapeutic potential in hypertension and peripheral vascular disease. Drugs 40, 903-949.

Chaouloff, F., 1995. Regulation of 5-HT receptors by corticosteroids: where do we stand? Fundam. Clin. Pharmacol. 9 (3), 219-233.

Checkly, S., 1992. Neuroendocrine mechanisms and the precipitation of depression by life events. Br. J. Psychiatry 15, 7-17.

Clark, D.M., Teasdale, J.D., 1982. Diurnal variation in clinical depression and accessibility of memories of positive and negative experiences. J. Abnorm. Psychology 91 (2), 87-95.

Eison, A.S., Eison, M.S., Torrente, J.R., Wright, R.N., Yocca, F.D., 1990. Nefazodone: preclinical pharmacology of a new antidepressant. Psychopharmacol. Bull. 26 (3), 311-315.

Ghosh, D., Biswas, N., Ghosh, P., 1990. Effect of lithium chloride on adrenocortical activity in male rats: evidence of dose and duration dependent responses. Indian J. Physiol. Pharmacol. 34 (4), 263-266.

Gorzalka, B.B., Hanson, L.A., 1998. Sexual behaviour and wet dog shakes in the male rat: regulation by corticosterone. Behav. Brain Res. 97, $143-151$.

Gorzalka, B.B., Hanson, L.A., Hong, J.J., 2001. Ketanserin attenuates the behavioural effects of corticosterone: implications for $5-\mathrm{HT}_{2 \mathrm{~A}}$ receptor regulation. Eur. J. Pharmacol. 428, 235-240.

Hanson, L., Gorzalka, B., Brotto, L., 1998. The antidepressant, nefazodone, 
attenuates corticosterone-induced increases in $5 \mathrm{HT}_{2 \mathrm{~A}}$ mediated behaviors in the female rat. Eur. J. Pharmacol. 342, 163-165.

Hennessy, J., Smotherman, W., Levine, S., 1976. Conditioned taste aversion and the pituitary adrenal system. Behav. Biol. 16, 413-424.

Hodges, J., Jones, M., 1963. The effect of injected corticosterone on the release of adrenocorticotrophic hormone in rats exposed to acute stress. J. Physiol. 67, 30-37.

Hotta, I., Yamawaki, S., Segawa, T., 1986. Long-term lithium treatment causes serotonin receptor down-regulation via serotonergic presynapses in rat brain. Neuropsychobiology 16, 19-26.

Kuroda, Y., Mikuni, M., Ogawa, T., Takahashi, K., 1992. Effect of ACTH adrenalectomy and the combination treatment on the density of $5-\mathrm{HT}_{2}$ receptor-binding sites in the neocortex of rat forebrain and 5- $\mathrm{HT}_{2}$ receptor mediated wet dog shake behaviors. Psychopharmacology 108, $27-32$.

Lesch, K., Mayer, S., Disselkamp-Tietze, J., Hoh, A., Wiesmann, M., Osterheider, M., Schulte, H., 1990. 5- $\mathrm{HT}_{1 \mathrm{~A}}$ receptor responsivity in unipolar depression. Evaluation of ipasapirone-induced ACTH and cortisol secretion in patients and controls. Biol. Psychiatry 27 (7), $620-628$

Lopez, J., Vazquez, D., Chalmers, D., Watson, S., 1997. Regulation of 5HT receptors and the hypothalamic-pituitary-adrenal axis implications for the neurobiology of suicide. Ann. N.Y. Acad. Sci. 836, $106-134$.

McKittrick, K.C., Blanchard, D., Blanchard, R., McWean, B., Sakai, R.,
1995. Serotonin receptor binding in a colony model of chronic social stress. Biol. Psychiatry 37, 383-393.

Moorman, J., Leslie, R., 1998. Paradoxical effects of lithium on serotonergic receptor function: an immunocytochemical, behavioral and autoradiographic study. Neuropharmacology 37, 357-374.

Olivier, B., Gommans, J., Van der Gugten, J., Bouwknecht, J., Herremans, A., Patty, T., Hijzen, T., 1999. Stimulus properties of the selective 5-HT reuptake inhibitor fluvoxamine in conditioned taste aversion procedures. Pharmacol. Biochem. Behav. 64 (2), 213-220.

Peeters, B.W., Broekkamp, C.L., 1994. Involvement of corticosteroids in the processing of stressful life-events. A possible implication for the development of depression. J. Steroid Biochem. Mol. Biol. 49, $417-427$.

Riley, A., Baril, L., 1976. Conditioned aversions: a bibliography. Anim. Learn. Behav. 4, 1S-13S.

Schless, A.P., Schwartz, L., Goetz, C., Mendels, J., 1974. How depressives view the significant life events. Br. J. Psychiatry 125 (0), 406-410.

Smotherman, W.P., 1985. Glucocorticoids and other hormonal substrates of conditioned taste aversion. Ann. N.Y. Acad. Sci. 443, 126-144.

Taylor, D.P., Carter, R.B., Eison, A.S., Mullins, U.L., Smith, H.L., Torrente, J., Wright, R., Yocca, F.D., 1995. Pharmacology and neurochemistry of nefazodone, a novel antidepressant drug. J. Clin. Psychiatry 56, 3-11.

Wegener, G., Smith, D.F., Rosenberg, R., 1997. 5- $\mathrm{HT}_{1 \mathrm{~A}}$ receptors in lithium-induced conditioned taste aversion. Psychopharmacology 133, $51-54$. 